\title{
Protection against live rotavirus challenge in mice induced by parenteral and mucosal delivery of VP6 subunit rotavirus vaccine
}

\author{
Suvi Lappalainen ${ }^{1}$ - Ana Ruth Pastor ${ }^{2}$ Maria Malm ${ }^{1}$ - Vanessa López-Guerrero ${ }^{3}$. \\ Fernando Esquivel-Guadarrama ${ }^{3}$ - Laura A. Palomares ${ }^{2} \cdot$ Timo Vesikari $^{1}$ • \\ Vesna Blazevic ${ }^{1}$
}

Received: 24 February 2015/Accepted: 20 May 2015/Published online: 29 May 2015

(C) The Author(s) 2015. This article is published with open access at Springerlink.com

\begin{abstract}
Live oral rotavirus (RV) vaccines are part of routine childhood immunization but are associated with adverse effects, particularly intussusception. We have developed a non-live combined $\mathrm{RV}$ - norovirus (NoV) vaccine candidate consisting of human RV inner-capsid rVP6 protein and NoV virus-like particles. To determine the effect of delivery route on induction of VP6-specific protective immunity, BALB/c mice were administered a vaccine containing RV rVP6 intramuscularly, intranasally or a combination of both, and challenged with murine RV. At least $65 \%$ protection against RV shedding was observed regardless of delivery route. The levels of post-challenge serum VP6-specific IgA titers correlated with protection.
\end{abstract}

Keywords Rotavirus - VP6 · IgA · Intranasal · Intramuscular · Protection

Rotavirus (RV) causes severe gastroenteritis in infants and children under 5 years of age with high mortality and morbidity rates [1]. Currently, two live oral RV vaccines, the monovalent Rotarix ${ }^{\circledR}$ (GlaxoSmithKline) and the pentavalent Rotateq ${ }^{\circledR}$ (Merck), are licensed and used extensively [2, 3]. However, these oral vaccines are less efficacious in developing countries $[4,5]$ and are associated with safety concerns such as a risk of intussusception [6].

Vesna Blazevic

vesna.blazevic@uta.fi

1 Vaccine Research Center, University of Tampere Medical School, Biokatu 10, 33520 Tampere, Finland

2 Instituto de Biotecnología, Universidad Nacional Autónoma de México, Cuernavaca, Morelos, México

3 Facultad de Medicina, Universidad Autónoma del Estado de Morelos, Cuernavaca, Morelos, México
Non-live subunit RV vaccines are therefore considered as alternatives for RV immunization.

Correlates of protection against RV infection are not fully understood. Type-specific neutralizing antibodies against the external proteins VP4 and VP7 have a role in protective immunity after natural RV infection $[7,8]$, but their role in vaccine-induced protective immunity against severe RV gastroenteritis has not been shown. Although serum anti-RV antibody IgA titers as a correlate of protection have been disputed [9], the best surrogate marker for $\mathrm{RV}$ vaccine-induced protection appears to be a high level of serum RV IgA antibody targeted to the inner capsid protein VP6 [10, 11], which determines viral group $(\mathrm{A}-\mathrm{H})$ and subgroup (SGI, II, I+II, non-I/II for group A) specificity [12] and is highly conserved [13], immunogenic [14, 15] and the most abundant RV protein [12]. VP6 does not induce classical neutralizing antibodies, but it induces heterotypic cross-reactive protection in mice [16-18].

Norovirus (NoV) is another leading cause of acute gastroenteritis in children, with genogroups GI and GII being responsible for the majority of NoV cases [19]. For protection against childhood gastroenteritis, we have introduced a concept of vaccination against RV and NoV with a combined trivalent vaccine consisting of RV rVP6 protein and NoV GI.3 and GII.4 virus-like particles (VLPs) [20]. We have previously shown that a candidate combination vaccine delivered intramuscularly (IM) to mice was highly immunogenic [20], and intranasal (IN) immunization protected mice against murine RV challenge [21]. Delivery requirements for the NoV components in the induction of protective NoV immune response were published recently [22]. In this work, we compared IM and IN delivery and the combination of both for induction of VP6-specific protective immunity against RV challenge, and we examined humoral immune responses for correlation with protection. 
Human RV rVP6 protein (SGII) used for immunization and as antigen in ELISA was produced using a baculovirus expression system in Sf9 insect cells [23]. The trivalent RV-NoV combination vaccine was prepared by mixing the rVP6 tubules and NoV GI.3 and GII.4 VLPs in equal amounts [20].

Female 7-week-old BALB/c OlaHsd mice (5 mice/group) (Harlan, Horst, The Netherlands) were immunized IM or IN twice (at study weeks 0 and 3) with the trivalent vaccine containing $10 \mu \mathrm{g}$ or RV rVP6 per immunization point. Moreover, sequential IM and IN immunizations (4 mice/group) with $10 \mu \mathrm{g}$ of rVP6 alone were performed to determine whether administration at two distinct sites would enhance protection. No external adjuvants were used. Naïve mice receiving PBS served as controls. Pre-immune (week 0) and pre-challenge (week 5) tail blood samples of individual mice were collected, processed to obtain sera and diluted 1:100 in PBS. At week 6, mice were challenged orally with $1 \times 10^{4}$ focus-forming units (FFU) (100 times the diarrheal dose $\mathrm{DD}_{50}$ ) of the murine RV strain $\mathrm{EDIM}_{\mathrm{wt}}$ (SG non-I/II, G3P10[16]), originally obtained from Dr. Ward (Gamble Institute of Medical Research, Cincinnati, $\mathrm{OH}$ ). Fecal samples were collected prior to challenge (day 0) and daily for 8 days (days 1-8) after the challenge. Mice were euthanized at day 8 , when whole blood samples were also collected. The protocol for the study (permission number 167-2010) was approved by the Bioethics Committee of the Instituto de Biotecnologia (Universidad Nacional Autónoma de México).

RV VP6-specific pre- and post-challenge antibody responses were determined by measuring levels of anti-VP6 IgG and $\operatorname{IgA}$ in individual sera at 1:100 and two-fold dilution series by ELISA according to previously published procedures [20, 21].

The presence of RV antigen in fecal samples was determined using an antigen ELISA [16]. Fecal antigen shedding was expressed as the net $\mathrm{OD}_{405}$ value (the $\mathrm{OD}$ of the pre-challenge fecal sample subtracted from the OD of the post-challenge samples of the individual mouse).

The pre-immune sera of all mice were negative for antiVP6 IgG and IgA (data not shown). Robust systemic IgG responses were induced by each immunization route (Fig. 1a). Geometric mean titers (GMTs) of serum IgG achieved by the IM, IN and IM+IN routes were equivalent $(p=0.663)$. IN and IM+IN delivery elicited detectable IgA antibodies $(p=0.556)$, while IM immunization did not (Fig. 1b). No anti-VP6 antibodies were detected in sera of control mice prior to the challenge (Fig. 1a and b).

The quantity of RV antigen shed in fecal samples was determined up to 8 days post-challenge (Fig. 2a). A significant difference in viral shedding was detected between the mice immunized IM, IN and IM+IN and the control
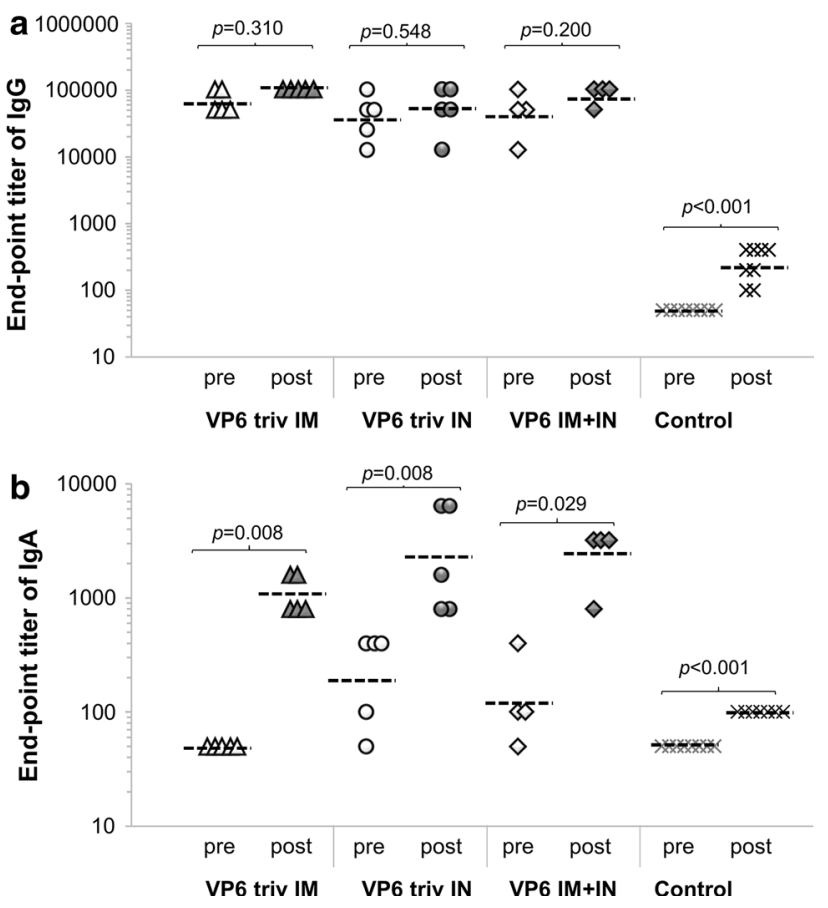

Fig. 1 Pre- and post-challenge VP6-specific $\operatorname{IgG}$ (a) and $\operatorname{IgA}$ (b) antibodies in sera of individual mice immunized IM and IN with the trivalent vaccine containing rVP6 (5 mice/group) or sequentially IM+IN with rVP6 (4 mice/group). A sample was considered ELISA positive if the optical density at $490 \mathrm{~nm}\left(\mathrm{OD}_{490}\right)$ was above the set cutoff value (mean $\mathrm{OD}_{490}$ of control mice $+3 \times \mathrm{SD}$ ) and $\geq 0.1$. All control mice were combined ( 8 mice/group). Endpoint titers of individual mice, expressed as $\log _{10}$ of the reciprocal of the highest sample dilution giving a positive reading, as well as geometric mean titers of the groups (-) at study weeks 5 (pre-challenge tailblood sample) and 7 (post-challenge termination sera) are shown. A titer of 50 was assigned for all negative samples, being a half of the starting serum dilution. The statistical differences between nonparametric observations of independent groups were assessed by Mann-Whitney U-test (SPSS Inc, Chicago, IL); $p \leq 0.05$ was considered to indicate a statistically significant difference

mice $(p=0.011)$, whereas the shedding between the immunized groups was not different $(p=0.514)$. The total antigen shedding of mice immunized IM and IN decreased $66 \%( \pm 12 \%)$ and $65 \%( \pm 18 \%)$ compared to the controls (Fig. 2a and b). Although sequential IM+IN immunization conferred a numerically higher protection rate $(84 \pm 5 \%)$ (Fig. 2b), it was not statistically different from the groups immunized IM or IN.

No correlation of pre-challenge titers of $\mathrm{IgG}$ $(\mathrm{r}=-0.455, p=0.127)$ or $\operatorname{IgA}(\mathrm{r}=-0.198, p=0.497)$ antibodies with protection rates was detected. After the RV challenge, VP6-specific serum IgG and IgA antibody titers increased in all VP6-immunized mice (Fig. 1a and b), but only the levels of the post-challenge $\operatorname{IgA}$ increased significantly compared to the pre-challenge levels $(p<0.03)$. Protection levels correlated with the levels of serum IgA after the challenge $(\mathrm{r}=0.607, p=0.006)$. Following the challenge, control mice also developed low levels of $\operatorname{IgG}$ 

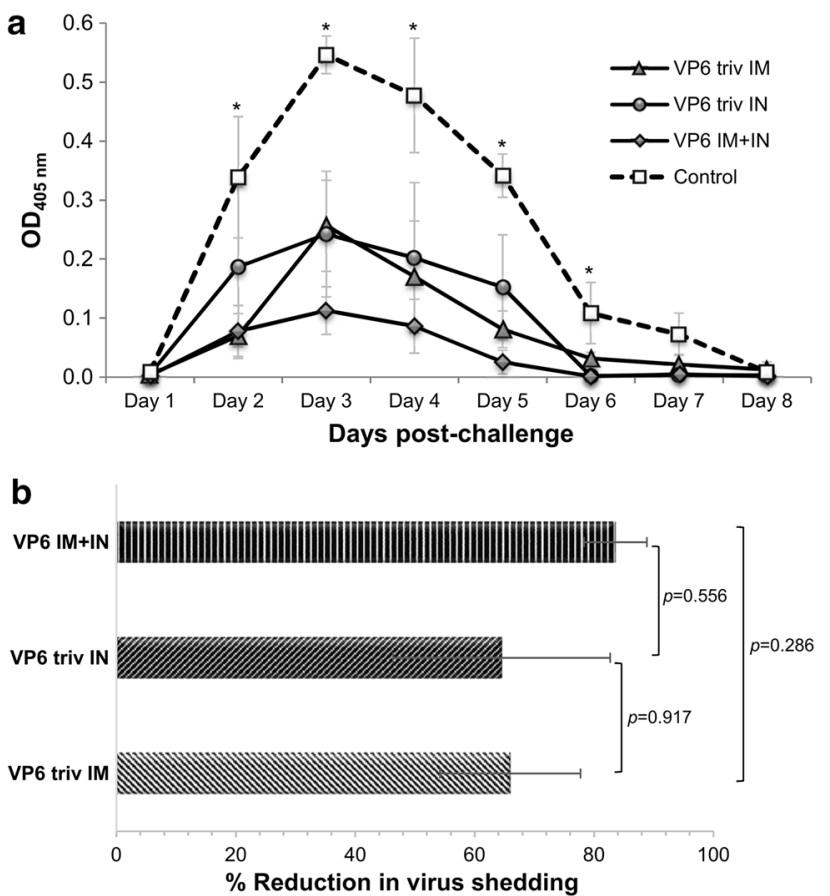

Fig. 2 Protection against RV shedding in immunized mice. Viral shedding curves $\left(\mathrm{OD}_{405}\right.$ versus day post-challenge) for each animal were plotted and the reduction in viral load was calculated by comparing the mean area under the shedding curve of the immunized mice to the mean area under the curve of the controls. a. Viral shedding curves of experimental groups. Each point represents the daily average of antigen shed per group with standard error of the mean. Asterisks $(*)$ indicate a significant difference ( $p \leq 0.05$; MannWhitney U-test) in daily shedding between the immunized and control mice. b. Reductions in virus shedding of VP6-immunized mice following challenge. Mean percent reductions of the experimental groups with standard error of the means are shown. A $>50 \%$ reduction in virus shedding was considered significant protection from virus challenge, as reported previously

$\left(\right.$ GMT $\left.\leq 2.5 \log _{10}\right)$ and IgA (GMT $\left.2 \log _{10}\right)$, but the titers were significantly lower than those of the vaccinated mice $(p<0.001)$.

RV VP6 has been proposed as a subunit vaccine candidate against $\mathrm{RV}$ by us [14, 20, 21, 23] and others [17]. It forms different oligomeric structures in vitro [24], which are highly immunogenic in mice without the need for external adjuvants $[14,20,21,25]$. Due to the repetitive multivalent antigenic structures, these oligomers are able to cross-link B-cell receptors very efficiently [26], whereas soluble VP6 generally requires an adjuvant for induction of an immune response [17]. Although the role of VP6 in protective immunity is still unclear, VP6 may be sufficient for protective immunity, as induction of protection against $\mathrm{RV}$ infection in mice and rabbits has been achieved with inactivated double-layered (dl) RV particles [27], dl2/6VLPs [28] and VP6 protein [17, 21, 25] without the surface VP4 and VP7 antigens. Unlike the surface proteins, antibodies to the inner capsid VP6 are non-neutralizing.
However, anti-VP6 IgA, but not $\operatorname{IgG}$, is able to inhibit RV replication intracellularly [18, 29].

Human RV-derived rVP6 protein given parenterally or mucosally induced similar levels of protection against RV $\mathrm{EDIM}_{\mathrm{wt}}$ infection. Protection was evaluated in an adult mouse model, which is an infection model but not a disease model, by measuring reduction in fecal RV antigen shedding after viral challenge [30]. Immunized mice showed significant reduction $(>65 \%)$ in virus shedding when compared to the controls. The protection was incomplete but of the order of magnitude that is achieved against any $\mathrm{RV}$ disease in humans after live RV vaccination. These results indicate efficacy of the rVP6-based vaccine in conferring protective immunity against live RV challenge independently of the delivery route. Similar reduction rates were previously published for mice immunized subcutaneously with rVP6 tubules [25]. Partial protection was also achieved with inactivated dl RV particles [27] and VP6 DNA vaccines after IM administration [31]. Protection close to $100 \%$ against shedding of two murine RV strains has been elicited after IN immunization with MBP-VP6 only after inclusion of an external adjuvant [17].

Although intestinal IgA was shown to be critical for RV clearance and protection in the mouse model [32], serum RV IgA targeted to VP6 has been considered the best surrogate marker for vaccine-induced protection in humans $[10,11]$. We detected a positive correlation between postchallenge VP6-specific serum IgA levels and the RV protection rate in mice. Both parenteral and mucosal delivery induced similar clearance of RV, even though only the IN and $\mathrm{IM}+\mathrm{IN}$ routes led to detectable pre-challenge serum IgA antibodies. IM immunized mice may have had undetectable pre-existing serum IgA level, which expanded rapidly after viral replication in the gut [33]. Viral replication possibly led to a significant increase in serum IgA titers in VP6-primed mice, which correlated with reduction in $\mathrm{RV}$ antigen shedding and therefore protection. However, evidence of a correlation of serum IgA with protection has been contradictory in animal models [34]. By contrast, correlation of protection with serum IgA has been presented in mice following IN immunization with dl2/6VLPs and cholera toxin [28].

In conclusion, the human RV rVP6 protein induced considerable protection in mice against live heterologous $\mathrm{RV}$ challenge, independently of the immunization route. These results highlight the importance of non-serotypespecific antibody responses induced using the highly conserved VP6 protein in heterotypic protection.

Acknowledgments We gratefully acknowledge the technical assistance given by the laboratory personnel of the Vaccine Research Center of University of Tampere Medical School and the Animal Facility of Instituto de Biotecnología (Universidad Nacional Autónoma de México). 
Conflict of interest The authors declare that they have no conflict of interest.

Open Access This article is distributed under the terms of the Creative Commons Attribution 4.0 International License (http:// creativecommons.org/licenses/by/4.0/), which permits unrestricted use, distribution, and reproduction in any medium, provided you give appropriate credit to the original author(s) and the source, provide a link to the Creative Commons license, and indicate if changes were made.

\section{References}

1. Yen C, Tate JE, Hyde TB et al (2014) Rotavirus vaccines: current status and future considerations. Hum Vaccin Immunother 10:1436-1448

2. Ruiz-Palacios GM, Perez-Schael I, Velazquez FR et al (2006) Safety and efficacy of an attenuated vaccine against severe rotavirus gastroenteritis. N Engl J Med 354:11-22

3. Vesikari T, Matson DO, Dennehy P et al (2006) Safety and efficacy of a pentavalent human-bovine (WC3) reassortant rotavirus vaccine. N Engl J Med 354:23-33

4. Zaman K, Dang DA, Victor JC et al (2010) Efficacy of pentavalent rotavirus vaccine against severe rotavirus gastroenteritis in infants in developing countries in Asia: a randomised, doubleblind, placebo-controlled trial. Lancet 376:615-623

5. Madhi SA, Cunliffe NA, Steele D et al (2010) Effect of human rotavirus vaccine on severe diarrhea in African infants. N Engl J Med 362:289-298

6. Patel MM, Lopez-Collada VR, Bulhoes MM et al (2011) Intussusception risk and health benefits of rotavirus vaccination in Mexico and Brazil. N Engl J Med 364:2283-2292

7. Offit PA, Blavat G (1986) Identification of the two rotavirus genes determining neutralization specificities. J Virol 57:376-378

8. Desselberger U, Huppertz HI (2011) Immune responses to rotavirus infection and vaccination and associated correlates of protection. J Infect Dis 203:188-195

9. Angel J, Franco MA, Greenberg HB (2012) Rotavirus immune responses and correlates of protection. Curr Opin Virol 2:419-425

10. Patel M, Glass RI, Jiang B, Santosham M, Lopman B, Parashar U (2013) A systematic review of anti-rotavirus serum IgA antibody titer as a potential correlate of rotavirus vaccine efficacy. J Infect Dis 208:284-294

11. Cheuvart B, Neuzil KM, Steele AD et al (2014) Association of serum anti-rotavirus immunoglobulin A antibody seropositivity and protection against severe rotavirus gastroenteritis: analysis of clinical trials of human rotavirus vaccine. Hum Vaccin Immunother 10:505-511

12. Estes M, Kapikian A (2007) Rotaviruses. In: Knipe D, Howley P, Griffin D, Lamb R, Martin M, Roizman B, Straus S (eds) Fields virology, 5th edn. Lippincott Williams and Wilkins, Philadelphia, pp 1917-1974

13. Tang B, Gilbert JM, Matsui SM, Greenberg HB (1997) Comparison of the rotavirus gene 6 from different species by sequence analysis and localization of subgroup-specific epitopes using sitedirected mutagenesis. Virology 237:89-96

14. Lappalainen S, Tamminen K, Vesikari T, Blazevic V (2013) Comparative immunogenicity in mice of rotavirus VP6 tubular structures and virus-like particles. Hum Vaccin Immunother 9:1991-2001

15. Svensson L, Sheshberadaran H, Vene S, Norrby E, Grandien M, Wadell G (1987) Serum antibody responses to individual viral polypeptides in human rotavirus infections. J Gen Virol $68(\mathrm{Pt}$ 3):643-651
16. Esquivel FR, Lopez S, Guitierrez-X L, Arias C (2000) The internal rotavirus protein VP6 primes for an enhanced neutralizing antibody response. Arch Virol 145:813-825

17. Choi AH, McNeal MM, Basu M et al (2002) Intranasal or oral immunization of inbred and outbred mice with murine or human rotavirus VP6 proteins protects against viral shedding after challenge with murine rotaviruses. Vaccine 20:3310-3321

18. Burns JW, Siadat-Pajouh M, Krishnaney AA, Greenberg HB (1996) Protective effect of rotavirus VP6-specific IgA monoclonal antibodies that lack neutralizing activity. Science 272:104-107

19. Debbink K, Lindesmith LC, Donaldson EF, Baric RS (2012) Norovirus immunity and the great escape. PLoS Pathog 8:e1002921

20. Tamminen K, Lappalainen S, Huhti L, Vesikari T, Blazevic V (2013) Trivalent combination vaccine induces broad heterologous immune responses to norovirus and rotavirus in mice. PLoS One 8:e70409

21. Lappalainen S, Pastor AR, Tamminen K et al (2014) Immune responses elicited against rotavirus middle layer protein VP6 inhibit viral replication in vitro and in vivo. Hum Vaccin Immunother 10:2039-2047

22. Malm M, Tamminen K, Vesikari T, Blazevic V (2015) Comparison of intramuscular, intranasal and combined administration of norovirus virus-like particle subunit vaccine candidate for induction of protective immune responses in mice. $\mathrm{J}$ Clin Cell Immunol 6:284. doi:10.4172/2155-9899.1000284

23. Blazevic V, Lappalainen S, Nurminen K, Huhti L, Vesikari T (2011) Norovirus VLPs and rotavirus VP6 protein as combined vaccine for childhood gastroenteritis. Vaccine 29:8126-8133

24. Lepault J, Petitpas I, Erk I et al (2001) Structural polymorphism of the major capsid protein of rotavirus. EMBO J 20:1498-1507

25. Pastor AR, Rodriguez-Limas WA, Contreras MA et al (2014) The assembly conformation of rotavirus VP6 determines its protective efficacy against rotavirus challenge in mice. Vaccine 32:2874-2877

26. Bachmann MF, Rohrer UH, Kundig TM, Burki K, Hengartner H, Zinkernagel RM (1993) The influence of antigen organization on B cell responsiveness. Science 262:1448-1451

27. McNeal MM, Rae MN, Conner ME, Ward RL (1998) Stimulation of local immunity and protection in mice by intramuscular immunization with triple- or double-layered rotavirus particles and QS-21. Virology 243:158-166

28. Siadat-Pajouh M, Cai L (2001) Protective efficacy of rotavirus 2/6-virus-like particles combined with CT-E29H, a detoxified cholera toxin adjuvant. Viral Immunol 14:31-47

29. Schwartz-Cornil I, Benureau Y, Greenberg H, Hendrickson BA, Cohen J (2002) Heterologous protection induced by the inner capsid proteins of rotavirus requires transcytosis of mucosal immunoglobulins. J Virol 76:8110-8117

30. Ward RL, McNeal MM, Sheridan JF (1990) Development of an adult mouse model for studies on protection against rotavirus. J Virol 64:5070-5075

31. Yang K, Wang S, Chang KO et al (2001) Immune responses and protection obtained with rotavirus VP6 DNA vaccines given by intramuscular injection. Vaccine 19:3285-3291

32. Blutt SE, Miller AD, Salmon SL, Metzger DW, Conner ME (2012) IgA is important for clearance and critical for protection from rotavirus infection. Mucosal Immunol 5:712-719

33. Coffin SE, Moser CA, Cohen S, Clark HF, Offit PA (1997) Immunologic correlates of protection against rotavirus challenge after intramuscular immunization of mice. J Virol 71:7851-7856

34. O'Neal CM, Harriman GR, Conner ME (2000) Protection of the villus epithelial cells of the small intestine from rotavirus infection does not require immunoglobulin A. J Virol 74:4102-4109 